\title{
Graphene Oxide Quantum Dots Promote Osteogenic Differentiation of Stem Cells from Human Exfoliated Deciduous Teeth via the Wnt/ $\beta$-Catenin Signaling Pathway
}

\author{
Xin Yang, ${ }^{1}$ Qi Zhao, ${ }^{2}$ JingWen Chen, ${ }^{1}$ Jiayue Liu, ${ }^{1}$ Jiacheng Lin, ${ }^{1}$ Jiaxuan $\mathrm{Lu},{ }^{1}$ Wenqing Li, ${ }^{1}$ \\ Dongsheng Yu $\mathbb{D}^{1},{ }^{1}$ and Wei Zhao $\mathbb{1}^{1}$ \\ ${ }^{1}$ Guanghua School of Stomatology, Hospital of Stomatology, Guangdong Provincial Key Laboratory of Stomatology, Sun Yat- \\ sen University, Guangzhou 510055, China \\ ${ }^{2}$ Xianning Central Hospital, The First Affiliated Hospital of Hubei University of Science And Technology, Xianning 437000, China \\ Correspondence should be addressed to Dongsheng Yu; yudsh@mail.sysu.edu.cn and Wei Zhao; zhaowei3@mail.sysu.edu.cn
}

Received 8 April 2020; Revised 5 January 2021; Accepted 23 January 2021; Published 9 February 2021

Academic Editor: Francisco J. Rodr guez Lozano

Copyright (@ 2021 Xin Yang et al. This is an open access article distributed under the Creative Commons Attribution License, which permits unrestricted use, distribution, and reproduction in any medium, provided the original work is properly cited.

\begin{abstract}
Graphene oxide quantum dots (GOQDs) are a carbon nanomaterial with broad potential for application in the field of nanomaterial biomedicine. Stem cells from human exfoliated deciduous teeth (SHEDs) play an important role in tissue engineering and regenerative medicine. This study investigated the effects of GOQDs on SHED osteogenic differentiation. GOQDs were synthesized; then, the proliferation of SHEDs incubated in GOQDs at different concentrations was evaluated; and the live cells were observed. We observed that live SHEDs incubated in GOQDs emitted green fluorescence in the absence of chemical dyes, and 1,10 , and $50 \mu \mathrm{g} / \mathrm{mL}$ GOQDs significantly promoted SHED proliferation. Culture with the osteogenic induction medium containing $10 \mu \mathrm{g} / \mathrm{mL}$ GOQDs induced calcium nodule formation, increased alkaline phosphatase (ALP) activity, and upregulated SHED mRNA and protein levels of OCN, RUNX2, COL I, and $\beta$-catenin. With the addition of Dickkopf 1 (DKK-1) or $\beta$-catenin knockdown, expression levels of the above mRNAs and proteins were decreased in GOQDtreated SHEDs. In summary, at a concentration of $10 \mu \mathrm{g} / \mathrm{mL}$, GOQDs promote SHED proliferation and osteogenic differentiation via the $\mathrm{Wnt} / \beta$-catenin signaling pathway. This work provides new ideas and fundamental information on interactions between GOQDs and SHEDs that are relevant for the biomedical engineering field.
\end{abstract}

\section{Introduction}

Inflammation, trauma, and tumors can cause bone tissue defects that seriously affect the patient's physical and mental health. A growing number of recent studies have focused on bone tissue engineering technologies to address these issues. This refers to the technique of bone regeneration and repair of bone defects by inducing osteogenic differentiation in stem cells, accurately forming the desired tissue for the defect in vitro, and then transplanting it back into the patient [14]. It is vital to continuously develop improved materials to induce osteogenic differentiation in stem cells and demonstrate the mechanisms.

In 2003, Miura and colleagues isolated a type of cell from the pulp of deciduous teeth that is highly self-renewable and has extensive proliferation and multidirectional differentiation potential that they called SHEDs [5]. There are many convenient ways to obtain SHEDs that do not cause trauma, and they carry a low risk of immune rejection or cross infection [6-8]. SHEDs can be obtained from fresh autologous tissue and used after cryopreservation; there is no obvious difference between the fresh and cryogenic SHEDs in their abilities to proliferate and undergo multidirectional differentiation [9]. This approach allows the establishment of a human pulp stem cell bank and provides a resource for stem cell therapy. SHEDs also have potent secretion and immune regulation properties $[10,11]$ and have been shown in animal models to have potential therapeutic effects for bone defects, diabetes, and autoimmune, neurodegenerative, liver, and kidney diseases. Some of these research results have been 
applied in clinical practice [10-12]. SHEDs are already playing an important role in the fields of tissue engineering and regenerative medicine. In a previous study, our group successfully separated and cultured SHEDs and demonstrated that $1 \mu \mathrm{g} / \mathrm{mL}$ GOQDs promoted SHED proliferation [13].

GOQDs are a carbon nanomaterial of several nanometers per dot and have important properties of quantum confinement effect, stable photoluminescence (PL), and good biocompatibility [14]. For these reasons, they have attracted much attention from scientists and exhibit promise for application in many fields, including bioimaging devices [15], drug delivery [16], electrochemical biosensors [17], fuel cells [18], and other useful products. Sun et al. [19] demonstrated that GOQDs can be used as fluorescence probes in fluorescence labeling fields and live cell imaging due to their excellent PL. Wang and colleagues [20] showed that GOQDs can be used to deliver genes, proteins, and drugs due to their ability to be structured over a large surface area. Choi et al. [21] reported that GOQDs can be loaded with medicine and used as a nontoxic light-sensitive agent in photodynamic therapy to treat clinical tumors. In addition, our group demonstrated that GOQDs at certain concentrations can induce osteogenic differentiation in stem cells, which supports their application in tissue regeneration [13]. In that work, we speculated that GOQDs may induce osteogenic differentiation in SHEDs via the $\mathrm{Wnt} / \beta$-catenin signaling pathway, which called for further investigation.

The Wnt/ $\beta$-catenin signaling pathway is a highly evolutionarily conserved pathway involved in regulating multiple biological processes [22]. The process of accumulating $\beta$ catenin in the cytoplasm and its subsequent translocation to the nucleus are important signs of pathway activation, which leads to the transcription of proteins in the $\mathrm{Wnt} / \beta$ catenin pathway and downstream activation of target genes [23]. Many recent studies have focused on the role of $\mathrm{Wnt} / \beta$-catenin signaling in bone tissue, and it has been shown to regulate osteogenic differentiation in human dental pulp stem cells (hDPSCs). Jiang et al. [24] found that after kif $3 a$ in hDPSCs was knocked down and Wnt3a was added to the osteogenic induction medium, the expression of the osteoblastic marker ALP and the Wnt/ $\beta$-catenin signaling pathway marker $\beta$-catenin were significantly increased. This suggested that kif3a might promote osteogenic differentiation of hDPSCs. Li et al. [25] demonstrated that a high concentration of basic fibroblast growth factor (bFGF) could inhibit $\beta$-catenin expression, thus inhibiting SHED osteogenic differentiation. Liu et al. [26] indicated that $\beta$-catenin can act as a downstream regulatory protein for telomerase reverse transcriptase. They found that low-concentration acetylsalicylic acid upregulated $\mathrm{Wnt} / \beta$-catenin pathway protein expression by improving the activity of telomerase reverse transcriptase and enhancing $\beta$-catenin expression, ultimately promoting SHED osteogenic differentiation. Our group has found that the expression trend for $\beta$-catenin following GOQD treatment is the same as that for osteoblastic markers, which induce osteogenic differentiation in SHEDs [13].

In the present study, we investigated the effects of GOQDs on SHED osteogenic differentiation and explored the underlying mechanism. First, we prepared GOQDs using a bottom-up method [27]; then, we evaluated the proliferation of SHEDs incubated with GOQDs at different concentrations, observing live cells with confocal laser scanning microscopy. We then quantified calcium nodules, ALP activity, and mRNA and protein levels related to osteogenic differentiation and the $\mathrm{Wnt} / \beta$-catenin signaling pathway. DKK-1 was used to inhibit the $\mathrm{Wnt} / \beta$-catenin signaling pathway, and $\beta$-catenin was knocked down to verify the mechanism by which GOQDs induce SHED osteogenic differentiation. We hypothesized that at a concentration of $10 \mu \mathrm{g} / \mathrm{mL}$, GOQDs would promote osteogenic differentiation via the $\mathrm{Wnt} / \beta$-catenin signaling pathway.

\section{Materials and Methods}

2.1. GOQD Preparation and Characterization. GOQDs were prepared by directly pyrolyzing citric acid (CA; Macklin, Shanghai, China) using the bottom-up method described previously [27]. In detail, $2.5 \mathrm{~g}$ CA and $25 \mathrm{~mL}$ doubledistilled water $\left(\mathrm{ddH}_{2} \mathrm{O}\right)$ were put into a beaker and heated to $200^{\circ} \mathrm{C}$ for $2-3 \mathrm{~h}$. During the heating process, the CA was dissolved, and the colorless liquid changed to yellow and finally to orange, indicating GOQD formation. Next, the orange liquid was dialyzed in a $500 \mathrm{Da}$ molecular weight dialysis bag for $48 \mathrm{~h}$ to remove CA, and then the liquid was freeze-dried to yield solid GOQDs, which were dissolved in tri-distilled water to obtain a GOQD suspension at a concentration of $1 \mathrm{mg} / \mathrm{mL}$ and sterilized with a $0.22 \mu \mathrm{m}$ filter membrane (EMD Millipore, Billerica, MA, USA).

The nanosize morphologies of the GOQDs were characterized by transmission electron microscopy (TEM; FEI Tecnai G2 Spirit, Hillsboro, OR, USA) at an acceleration voltage of $300 \mathrm{kV}$. The compositions of GOQDs were characterized by Fourier transform infrared spectrometry (FTIR; Bruker, Karlsruhe, Germany). The ultraviolet- (UV-) visible spectra of GOQDs were measured on a Lambda 950 spectrophotometer (PerkinElmer, Waltham, MA, USA). The fluorescence spectra of GOQDs under $365 \mathrm{~nm}$ excitation wavelengths were measured on a Cary Eclipse (Agilent Technologies, Santa Clara, CA, USA).

2.2. Proliferation Assay. Ethics committee approval was provided by the School of Stomatology, Sun Yat-sen University. SHEDs were isolated and identified as described previously [13]. The cytocompatibility of different concentrations of GOQDs was evaluated with a Cell Counting Kit-8 (CCK-8; Beyotime Institute of Biotechnology, Haimen, China). SHEDs were cultured in a culture medium, including Dulbecco's modified Eagle's medium (DMEM; Gibco, Thermo Fisher Scientific, Inc., Waltham, MA, USA) with $10 \%$ fetal bovine serum (FBS; Gibco) and 1\% penicillin/streptomycin (P/S; Gibco) at a concentration of $5 \times 10^{3}$ cells/well on 96well plates, and then the SHEDs were treated with GOQDs at concentrations of $1,10,50,100$, and $200 \mu \mathrm{g} / \mathrm{mL}$. After 1 , 3 , 5, and 7 days, the culture medium was replaced with $10 \mu \mathrm{L}$ CCK-8 solution and $100 \mu \mathrm{L}$ DMEM, and the plates were incubated at $37^{\circ} \mathrm{C}$ for $1 \mathrm{~h}$. The optical density (OD) at 
TABLE 1: Primer sequences used in qRT-PCR.

\begin{tabular}{|c|c|c|}
\hline Gene & Primer & Sequence \\
\hline OCN & $\begin{array}{l}\text { Forward } \\
\text { Reverse }\end{array}$ & $\begin{array}{c}5^{\prime} \text {-AGCAAAGGTGCAGCCTTTGT-3' } \\
5^{\prime} \text {-GCGCCTGGGTCTCTTCACT-3' }\end{array}$ \\
\hline RUNX2 & $\begin{array}{l}\text { Forward } \\
\text { Reverse }\end{array}$ & $\begin{array}{l}5^{\prime} \text {-CCACTGAACCAAAAAGAAATCCC-3' } \\
5^{\prime} \text {-GAAAACAACACATAGCCAAACGC-3' }\end{array}$ \\
\hline COL I & $\begin{array}{l}\text { Forward } \\
\text { Reverse }\end{array}$ & $\begin{array}{l}5^{\prime} \text {-CGATGGATTCCAGTTCGAGTATG-3' } \\
5^{\prime} \text {-TGTTCTTGCAGTGGTAGGTGATG-3' }\end{array}$ \\
\hline$\beta$-Catenin & $\begin{array}{l}\text { Forward } \\
\text { Reverse }\end{array}$ & $\begin{array}{c}5^{\prime} \text {-AAGTTCTTGGCTATTACGACA-3' } \\
5^{\prime} \text {-ACAGCACCTTCAGCACTCT-3' }\end{array}$ \\
\hline GAPDH & $\begin{array}{l}\text { Forward } \\
\text { Reverse }\end{array}$ & $\begin{array}{l}5^{\prime} \text {-TCTCCTCTGACTTCAACAGCGACA-3' } \\
5^{\prime} \text {-СCCTGTTGCTGTAGCCAAATTCGT-3' }\end{array}$ \\
\hline
\end{tabular}

$450 \mathrm{~nm}$ was measured using a microplate reader (Tecan, Männedorf, Switzerland).

2.3. Live Cell Imaging. The morphology of SHEDs treated with GOQDs was observed via confocal laser scanning microscopy (Zeiss, Oberkochen, Germany). SHEDs were plated on Petri dishes at a concentration of $1 \times 10^{4}$ cells/dish, then treated with GOQDs at concentrations of 1,10 , and $50 \mu \mathrm{g} / \mathrm{mL}$. After 3 days, SHEDs were washed with phosphate-buffered saline (PBS; Hyclone, Logan, UT, USA) and imaged.

2.4. Alizarin Red Staining. SHEDs were seeded in six-well plates; upon reaching $70-80 \%$ confluence, they were treated with the osteogenic induction medium (OIM) created from DMEM with $10 \%$ FBS, $1 \% \mathrm{P} / \mathrm{S}, 1 \mu \mathrm{M}$ dexamethasone (Sigma-Aldrich, St. Louis, MO, USA), $10 \mathrm{mM} \beta$-glycerophosphate (Sigma-Aldrich), and $50 \mu \mathrm{M}$ ascorbic acid (SigmaAldrich), with 1,10 , or $50 \mu \mathrm{g} / \mathrm{mL}$ GOQDs, for 14 days. After culturing, the cells were fixed in $4 \%$ paraformaldehyde for $30 \mathrm{~min}$, rinsed with PBS, stained with alizarin red (Cyagen Biosciences Inc., Guangzhou, China) for $30 \mathrm{~min}$ at room temperature, and washed with PBS. Finally, mineralized nodules were photographed with an inverted microscope (Axiovert 40; Zeiss). The control group was incubated in OIM without GOQDs.

2.5. ALP Activity Assay. SHEDs were seeded in 24-well plates, and when $70-80 \%$ confluence was reached, they were cultured in OIM with 1,10 , or $50 \mu \mathrm{g} / \mathrm{mL}$ GOQDs for 3 and 7 days. The control group was incubated with OIM without GOQDs. ALP activity was determined using an ALP assay kit (Nanjing Jiancheng Bioengineering Institute, Nanjing, China), according to the manufacturer's instructions.

2.6. Quantitative Real-Time Reverse Transcription Polymerase Chain Reaction ( $q R T-P C R)$. SHEDs were seeded in six-well plates, and when they reached $70-80 \%$ confluence, they were cultured in OIM, with 1,10 , or $50 \mu \mathrm{g} / \mathrm{mL}$ GOQDs for 7 and 14 days. The control group was incubated in OIM without GOQDs. Total RNA was extracted using the TRIzol reagent (Invitrogen, Carlsbad, CA, USA), following the manufacturer's protocol. PrimeScript ${ }^{\mathrm{TM}}$ RT Master Mix (Takara
Bio Inc., Shiga, Japan) was used to convert messenger RNA (mRNA) into complementary DNA (cDNA). Then, the cDNA was quantified using qRT-PCR, which was performed on a LightCycler 480 Detection System (Roche, Basel, Switzerland) with an SYBR Green Kit (Roche) using genespecific primers. The primer sequences are shown in Table 1. Glyceraldehyde 3-phosphate dehydrogenase (GAPDH) was used as an internal control.

2.7. Western Blot (WB) Assay. SHEDs were seeded in six-well plates, and when they reached $70-80 \%$ confluence, they were cultured in OIM with 1,10 , or $50 \mu \mathrm{g} / \mathrm{mL}$ GOQDs for 14 days. The control group was incubated in OIM without GOQDs. Briefly, the radioimmunoprecipitation assay buffer (KeyGen BioTECH, Nanjing, China) containing $1 \mathrm{mmol} / \mathrm{L}$ protease inhibitor cocktail (CWBIO, Beijing, China) was used to lyse cells, a bicinchoninic acid (BCA) assay kit (CWBIO) was used to measure protein concentrations, and sodium dodecyl sulfate-polyacrylamide gel electrophoresis (SDS-PAGE, CWBIO) was used to separate proteins that were then transferred onto polyvinylidene fluoride membranes (Millipore). Next, $5 \%$ fat-free milk in Tris-buffered saline with Tween (TBST; $10 \mathrm{mmol} / \mathrm{L}$ Tris- $\mathrm{HCl}, 50 \mathrm{mmol} / \mathrm{L} \mathrm{NaCl}$, and $0.25 \%$ Tween 20) was used to block membranes for $1 \mathrm{~h}$ at room temperature, which were then incubated with primary antibodies (anti-osteocalcin (OCN) and anti-collagen I (COL I), $1: 500$, Abcam, Cambridge, UK; anti-runt-related transcription factor-2 (RUNX2), anti- $\beta$-catenin, and antiGAPDH, $1: 1000$, Cell Signaling Technology (CST), Danvers, MA, USA) for $18 \mathrm{~h}$ at $4^{\circ} \mathrm{C}$. Finally, the membranes were incubated with horseradish peroxidase-conjugated anti-rabbit secondary antibodies $(1: 2000$, CST), and bands were detected with an enhanced chemiluminescence detection system (Millipore) and quantified using ImageJ v1.47 software (National Institutes of Health, Bethesda, MD, USA). GAPDH was used as an internal control.

2.8. Effects of DKK-1. After the above steps, SHEDs were treated with GOQDs at a concentration of $10 \mu \mathrm{g} / \mathrm{mL}$ to induce osteogenic differentiation for the next experiment. SHEDs were seeded in six-well plates, and when they reached $70-80 \%$ confluence, they were cultured in OIM with GOQDs 


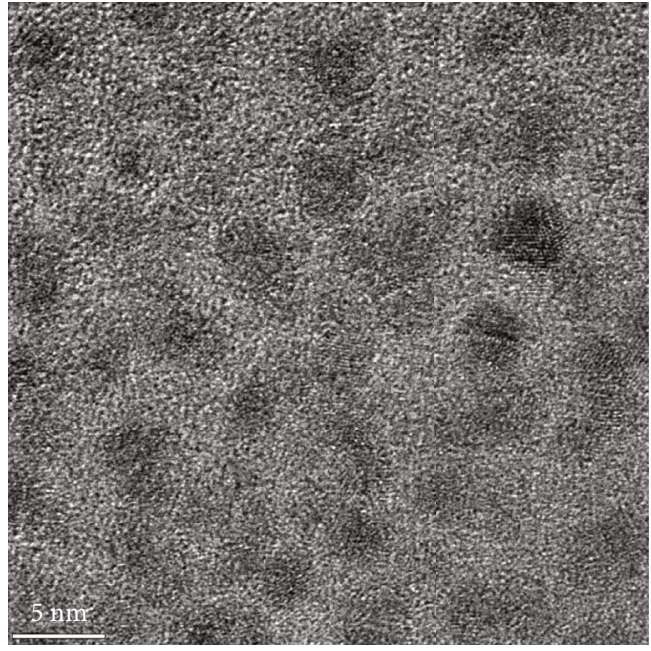

(A)

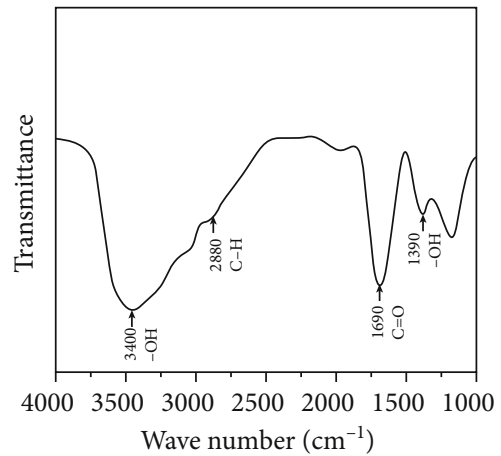

(b)

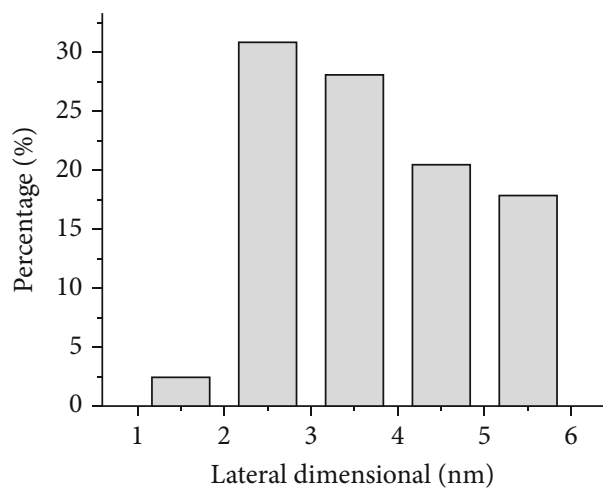

(B)

(a)

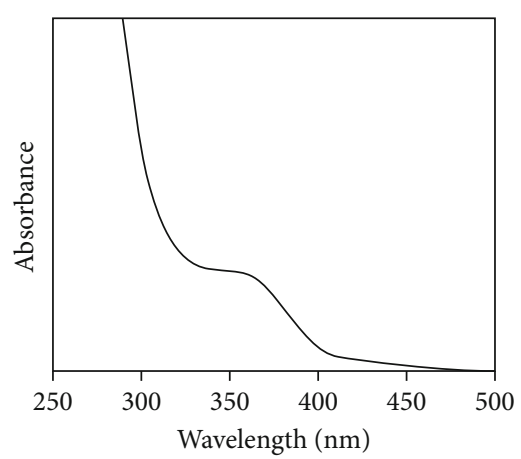

(c)

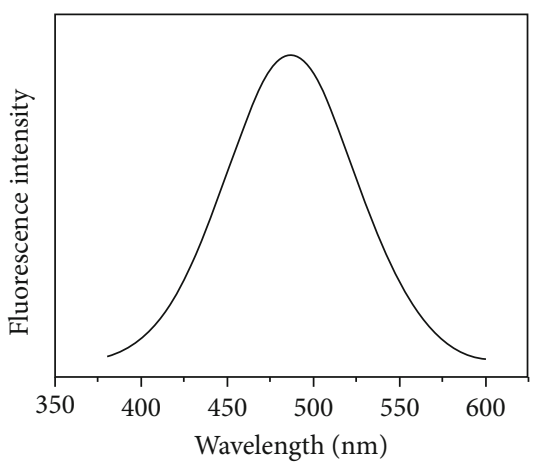

(d)

FIGURE 1: Characterization of GOQDs. (a) (A) TEM image of GOQDs. (B) Lateral size distribution of GOQDs from (A). (b) FTIR spectroscopy of GOQDs. (c) UV-visible spectrum of GOQDs. (d) PL spectrum of GOQDs excited at a wavelength of $365 \mathrm{~nm}$.

and with or without $100 \mathrm{ng} / \mathrm{mL}$ DKK-1. The cells were divided into three groups: control (SHEDs cultured in OIM alone), DKK-1 (SHEDs cultured in OIM, DKK-1, and GOQDs), and GOQD (SHEDs cultured in OIM and GOQDs). The effects of DKK-1 relating to the GOQDmediated induction of osteogenic differentiation in SHEDs were confirmed via qRT-PCR and WB assays.

2.9. Lentiviral Infection. SHEDs were seeded into a culture flask, and when they reached $50 \%$ confluence, they were treated with DMEM containing enhanced green fluorescence protein-labeled (EGFP) $\beta$-catenin small interfering RNA (siRNA) lentivirus (Shanghai Genechem Co., Ltd., Shanghai, China). siRNA against $\beta$-catenin GTATTTGAAGTATACC ATA and a nonspecific shRNA construct were designed and cloned onto an hU6-MCS-CMV-EGFP vector. Control viruses that contained the EGFP tag (Shanghai Genechem Co., Ltd.) were also provided. After incubation for $10 \mathrm{~h}$ at $37^{\circ} \mathrm{C}$ and $5 \% \mathrm{CO}_{2}$, the supernatant was removed and replaced with a culture medium for 3 days. Infected cells were 
imaged with a fluorescence inverted microscope (Zeiss), and the knockdown effect was confirmed via qRT-PCR and WB assays. SHEDs infected with $\beta$-catenin recombinant lentiviruses or empty lentiviral vectors were defined as the $\beta$ catenin-KD group and the control-si group, respectively.

2.10. Effects of $\beta$-Catenin. SHEDs were treated with $10 \mu \mathrm{g} / \mathrm{mL}$ GOQDs to induce osteogenic differentiation for the next experiment. They were seeded in six-well plates, and upon reaching 70-80\% confluence, they were cultured in OIM that included GOQDs. The cells were independently divided into three groups: control-si (SHEDs infected with control viruses and cultured in OIM alone), GOQD-si (SHEDs infected with control viruses and cultured in OIM and GOQDs), and $\beta$ catenin-si (SHEDs infected with $\beta$-catenin recombinant lentiviruses and cultured in OIM and GOQDs). The effects of $\beta$ catenin on GOQD-mediated induction of osteogenic differentiation in SHEDs were confirmed via qRT-PCR and WB assays.

2.11. Statistical Analysis. The data are shown as means \pm standard deviations. One-way analysis of variance was used to perform statistical analyses, and the Bonferroni method was used for multiple comparisons. Differences were considered significant at $p<0.05$. SPSS 20.0 software (SPSS Inc., Chicago, Illinois, USA) was used for all statistical analyses.

\section{Results}

3.1. Synthesized GOQDs. GOQD morphology was observed using TEM (Figure 1(a)); they were dispersed and had dot sizes with diameters largely under $10 \mathrm{~nm}$. Surface chemistry was investigated by FTIR (Figure 1(b)), and absorption bands at $3400 \mathrm{~cm}^{-1}$ and $1390 \mathrm{~cm}^{-1}$ were observed due to stretching in hydroxyl groups $(-\mathrm{OH})$ and stretching vibrations in carboxyl groups $(\mathrm{C}=\mathrm{O})$ at $1690 \mathrm{~cm}^{-1}$ and hydrocarbon groups $(\mathrm{C}-\mathrm{H})$ at $2880 \mathrm{~cm}^{-1}$. As shown in Figures $1(\mathrm{c})$ and $1(\mathrm{~d})$, the excitation wavelength of GOQDs is $365 \mathrm{~nm}$, and the emission spectrum ranges from 380 to $600 \mathrm{~nm}$, indicating that GOQDs have PL.

3.2. GOQDs Promote SHED Proliferation. CCK-8 assays were used to evaluate SHED viability (Figure 2). The results showed that 1,10 , and $50 \mu \mathrm{g} / \mathrm{mL}$ GOQDs significantly promoted SHED proliferation at days 3, 5, and 7. At the highest concentration of $200 \mu \mathrm{g} / \mathrm{mL}$, GOQDs slightly suppressed cell viability (but without a statistical difference). Therefore, we chose the 1,10 , and $50 \mu \mathrm{g} / \mathrm{mL}$ concentrations of GOQDs to perform the following assays.

\subsection{SHEDs Incubated in GOQDs Emitted Green Fluorescence.} In vitro cell images are shown in Figure 3. After incubation with GOQDs at concentrations of 1,10 , and $50 \mu \mathrm{g} / \mathrm{mL}$, SHEDs emitted green fluorescence, predominantly in the cytoplasm, under illumination at a wavelength of $488 \mathrm{~nm}$. SHEDs that were not exposed to GOQDs and imaged under the same conditions did not show any fluorescence. In all groups, SHEDs showed a normal spindle-like or fibroblastlike morphology.

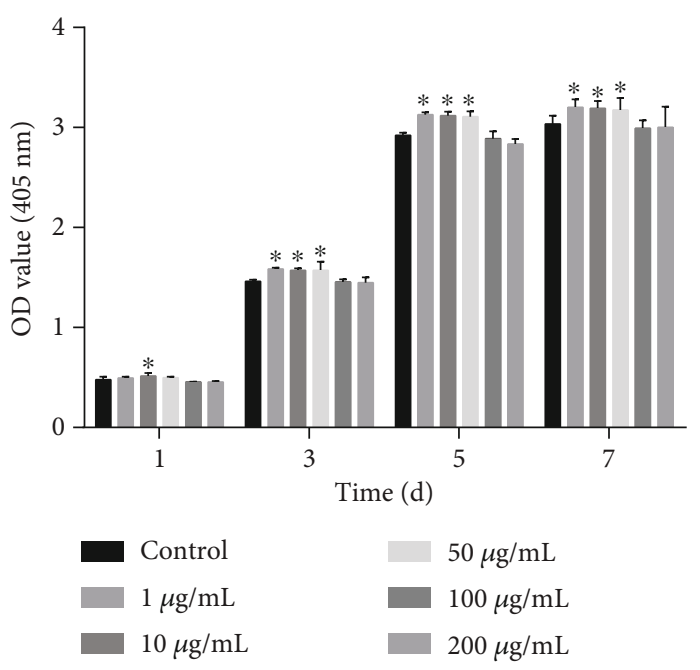

FIgURE 2: The proliferation of SHEDs incubated with different concentrations $(0,1,10,50,100$, and $200 \mu \mathrm{g} / \mathrm{mL})$ of GOQDs for 1 , 3,5 , and 7 days. ${ }^{*} p<0.05$ vs. the control group.

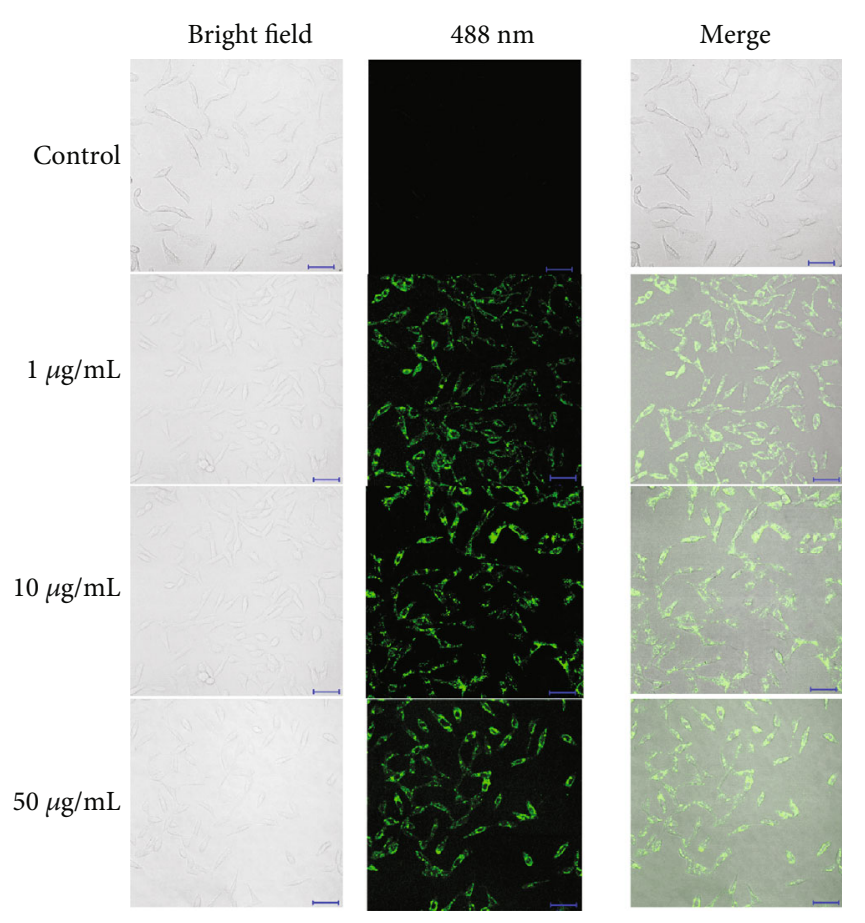

FIgURe 3: Confocal laser scanning microscopy images of SHEDs incubated with 1,10 , and $50 \mu \mathrm{g} / \mathrm{mL}$ of GOQDs, respectively, for 3 days. Scale bar, $100 \mu \mathrm{m}$.

3.4. Mineralized Nodule Formation. Calcium nodules were formed in all four groups after osteogenic induction for 14 days (Figure 4(a)). Calcium nodule formation in the 1 and $10 \mu \mathrm{g} / \mathrm{mL}$ GOQD groups was greater than that in the control group, and it was less evident in the $50 \mu \mathrm{g} / \mathrm{mL}$ GOQD group. Calcium nodule formation in the $1 \mu \mathrm{g} / \mathrm{mL}$ group was greater than that in the $50 \mu \mathrm{g} / \mathrm{mL}$ group but less than that in the $10 \mu \mathrm{g} / \mathrm{mL}$ group. The highest level of mineralization was observed in the $10 \mu \mathrm{g} / \mathrm{mL}$ group. 
(A)

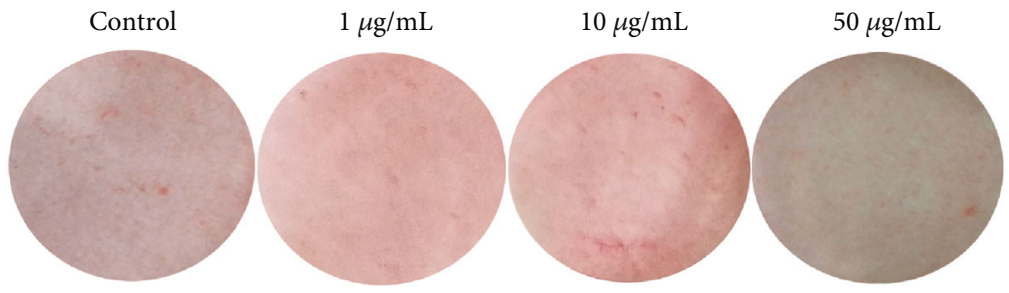

(B)
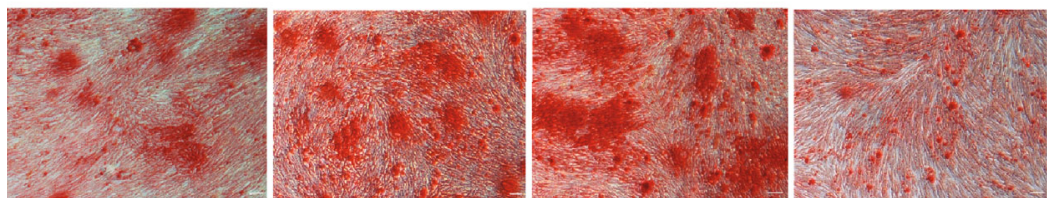

(a)

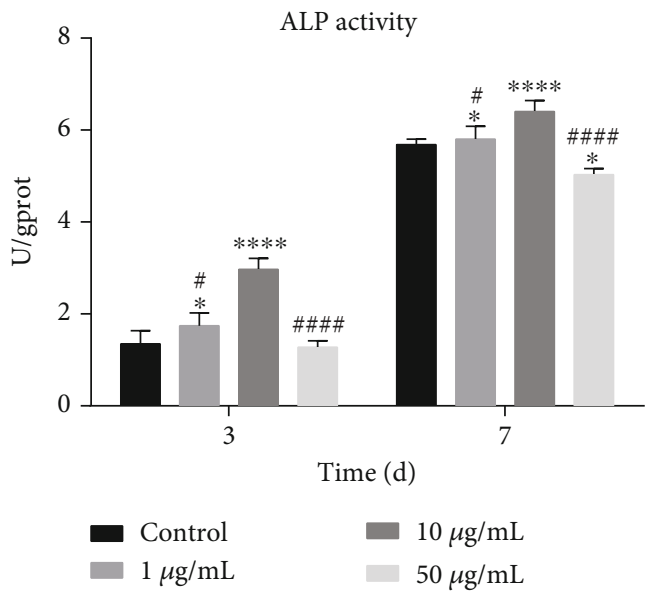

(b)

FIGURE 4: SHEDs were cultured in the osteogenic induction medium containing GOQDs. Osteogenic differentiation was detected by (a) alizarin red S staining for 14 days: (A) optical photos and (B) microscopic images. (b) ALP activity after 3 and 7 days. Scale bar, $100 \mu \mathrm{m}$. * $p<0.05,{ }^{* *} p<0.01,{ }^{* * *} p<0.001$, and ${ }^{* * * *} p<0.0001$ vs. the control group. ${ }^{\#} p<0.05,{ }^{\# \#} p<0.01,{ }^{\# \# \#} p<0.001$, and ${ }^{\# \# \#} p<0.0001$ vs. the $10 \mu \mathrm{g} / \mathrm{mL}$ GOQD group.

3.5. GOQDs Increased ALP Activity in SHEDs. After osteogenic differentiation of SHEDs for 3 and 7 days (Figure 4(b)), ALP activity in the $10 \mu \mathrm{g} / \mathrm{mL}$ GOQD group was significantly higher than that in the other groups. ALP activity was increased in the 1 and $10 \mu \mathrm{g} / \mathrm{mL}$ GOQD groups compared to the control group, and it was significantly decreased in the $50 \mu \mathrm{g} / \mathrm{mL}$ GOQD group.

3.6. GOQDs Upregulated SHED mRNA Levels. The qRT-RCR results following GOQD-induced osteogenic differentiation of SHEDs for 7 days are shown in Figure 5(a). The expression levels of the osteogenic mRNAs OCN, RUNX2, and COL I and the $\mathrm{Wnt} / \beta$-catenin signaling pathway-related mRNA $\beta$-catenin were higher in the 1 and $10 \mu \mathrm{g} / \mathrm{mL}$ GOQD groups and lower in the $50 \mu \mathrm{g} / \mathrm{mL}$ GOQD group. After 14 days of induction (Figure 5(b)), mRNA expression in the $10 \mu \mathrm{g} / \mathrm{mL}$ GOQD group was significantly higher than that in the other groups.

3.7. GOQDs Upregulated SHED Protein Levels. Protein levels of OCN, RUNX2, COL I, and $\beta$-catenin were analyzed after 14 days of osteogenic-inducing culture. As shown in
Figures 5(c) and 5(d), expression was distinctly higher in the 1 and $10 \mu \mathrm{g} / \mathrm{mL}$ groups and distinctly lower in the $50 \mu \mathrm{g} / \mathrm{mL}$ group compared to the control group. Moreover, it was greater in the $10 \mu \mathrm{g} / \mathrm{mL}$ group than in the $1 \mu \mathrm{g} / \mathrm{mL}$ group.

3.8. DKK-1 Suppresses Osteoblastic Differentiation of GOQDTreated SHEDs. As shown in Figure 6, OCN, RUNX2, COL I, and $\beta$-catenin mRNA and protein levels were significantly lower in the control and DKK-1 groups compared to the GOQD group. The lowest level was observed in the DKK-1 group.

3.9. Knockdown of $\beta$-Catenin Suppresses Osteoblastic Differentiation in GOQD-Treated SHEDs. Lentiviral gene transfer efficiency in SHEDs was high after $72 \mathrm{~h}$ transfection (Figure $7(\mathrm{a})$ ). At the mRNA and protein levels, $\beta$-catenin was approximately $50 \%$ lower in the $\beta$-catenin-KD group than in the control-si group, suggesting that $\beta$-catenin was effectively silenced (Figures 7(b)-7(d)).

To investigate the differentiation potential of SHEDs after $\beta$-catenin knockdown, we measured mRNA and protein 

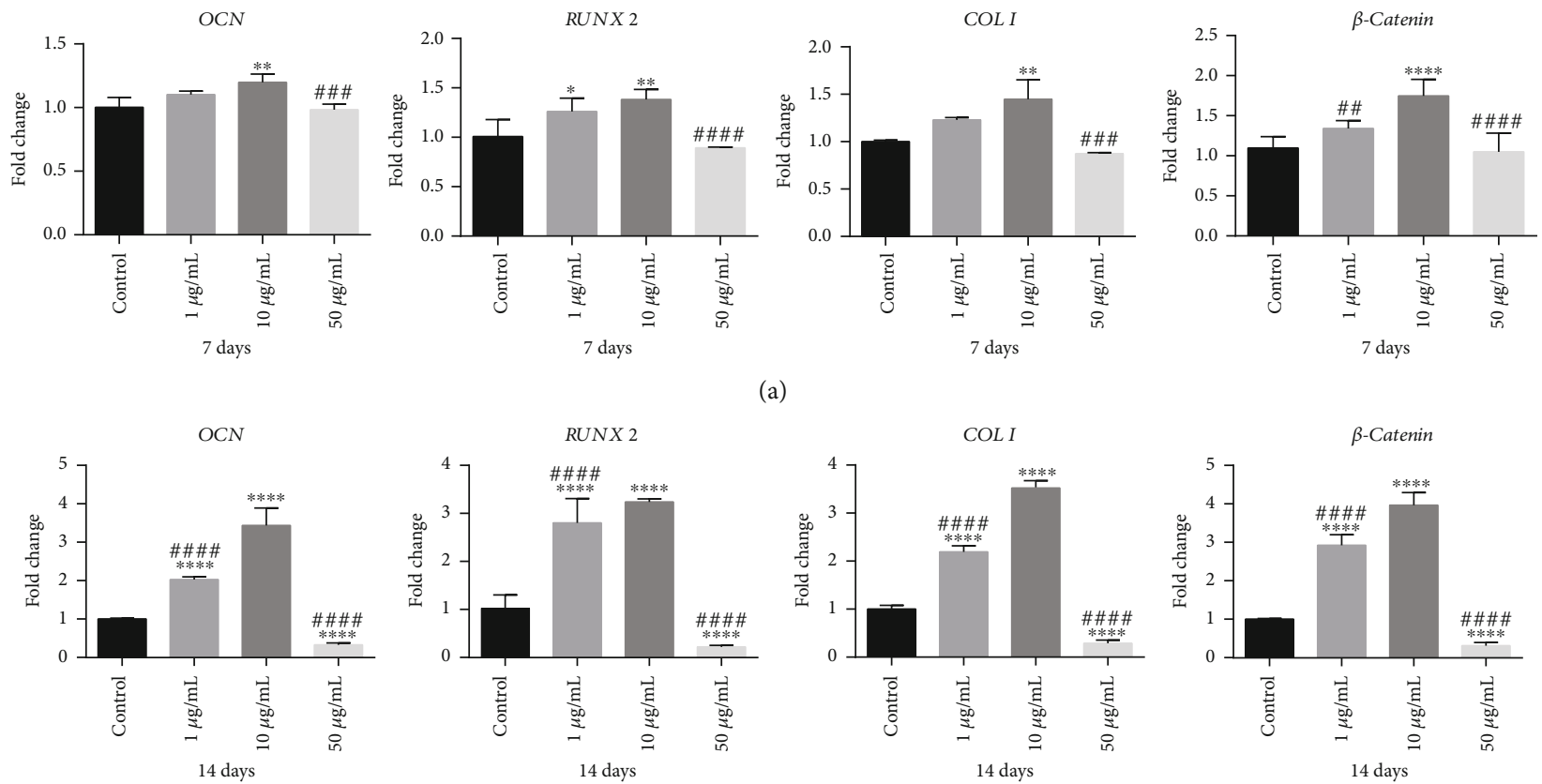

(a)
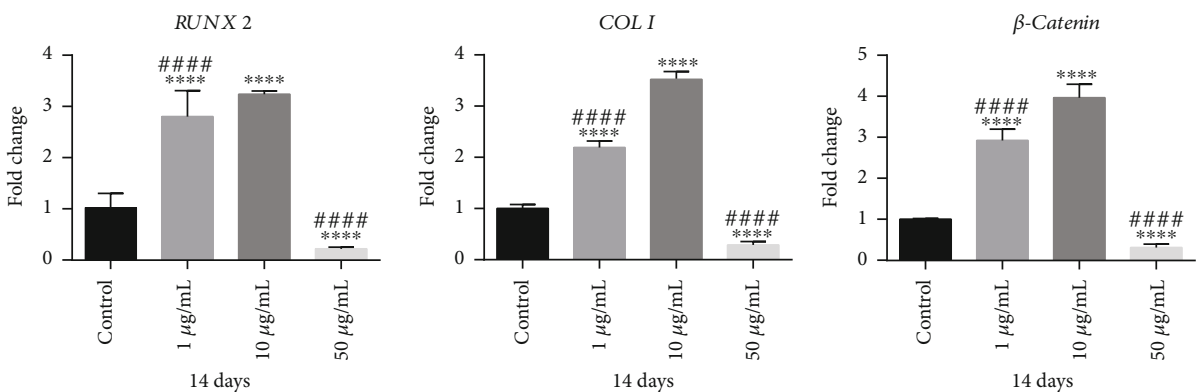

(b)

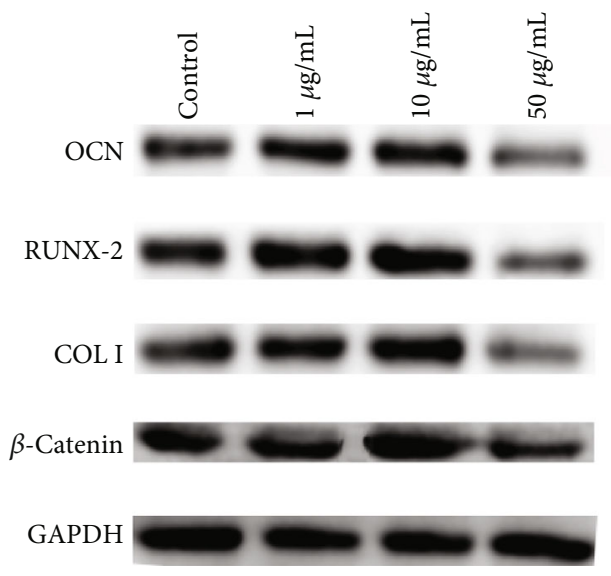

(c)
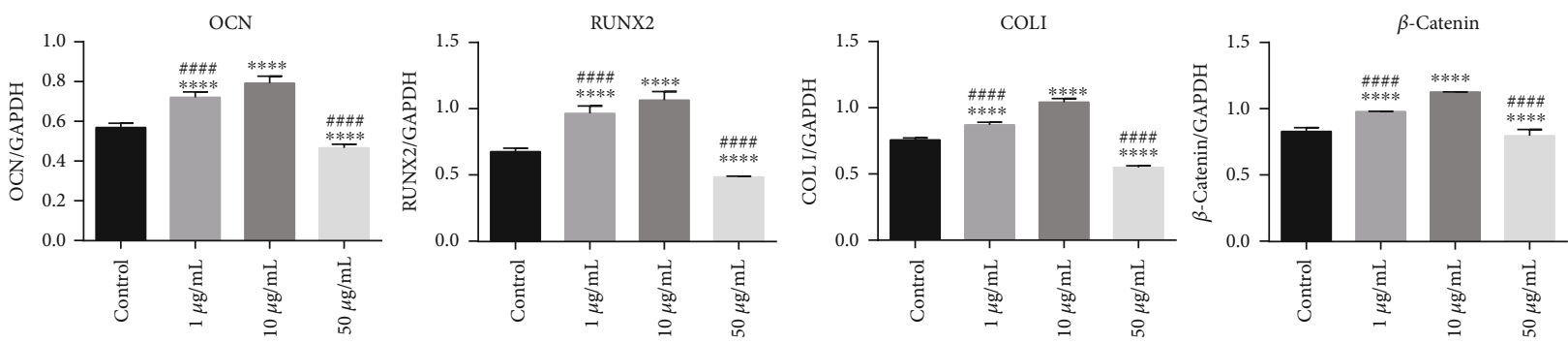

(d)

FIGURE 5: SHEDs were cultured in the osteogenic induction medium containing GOQDs. (a) mRNA extracted at 7 days. (b) mRNA extracted at 14 days. (c) Protein extracted at 14 days. (d) Quantification of protein levels. ${ }^{*} p<0.05,{ }^{* *} p<0.01,{ }^{* * *} p<0.001$, and ${ }^{* * * *} p<0.0001$ vs. the control group. ${ }^{\#} p<0.05,{ }^{\# \#} p<0.01,{ }^{\# \# \#} p<0.001$, and ${ }^{\# \# \#} p<0.0001$ vs. the $10 \mu \mathrm{g} / \mathrm{mL}$ GOQD group.

levels of OCN, RUNX2, COL I, and $\beta$-catenin. After the induction of osteogenic differentiation in SHEDs, $\beta$-catenin knockdown resulted in lower values for the above mRNAs and proteins in the $\beta$-catenin-si group compared to the control-si and GOQD-si groups (Figure 8).

\section{Discussion}

GOQD synthesis can be divided into two methods: top-down and bottom-up [14, 27]. In the top-down method, graphene or graphite-related materials are cut to the size of a quantum 

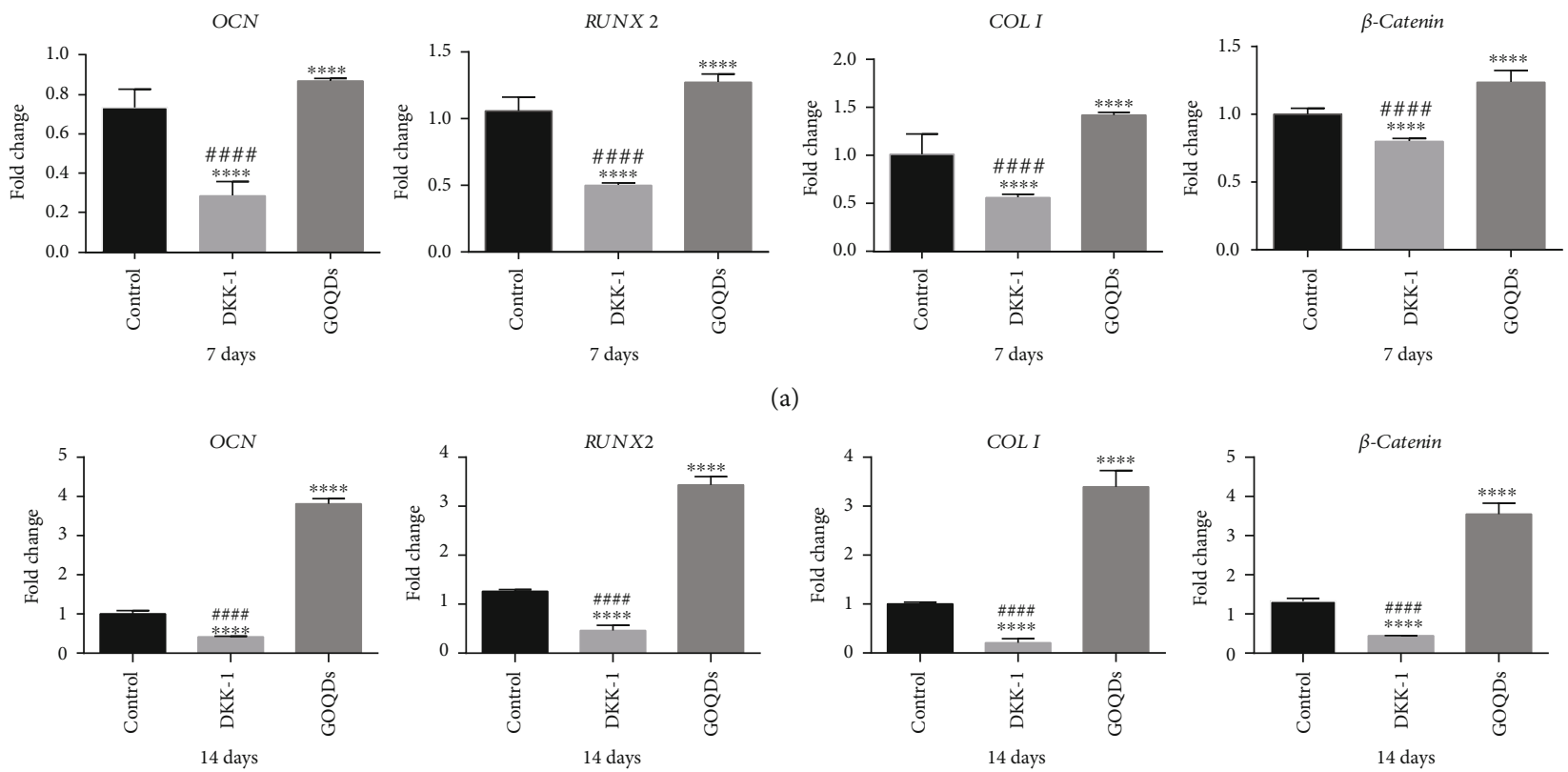

(a)
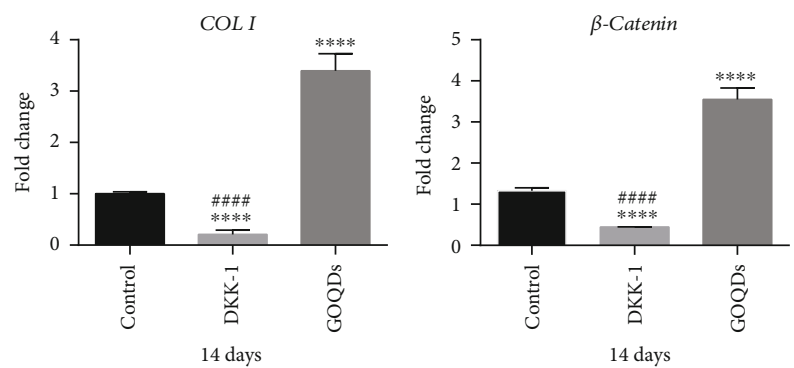

(b)

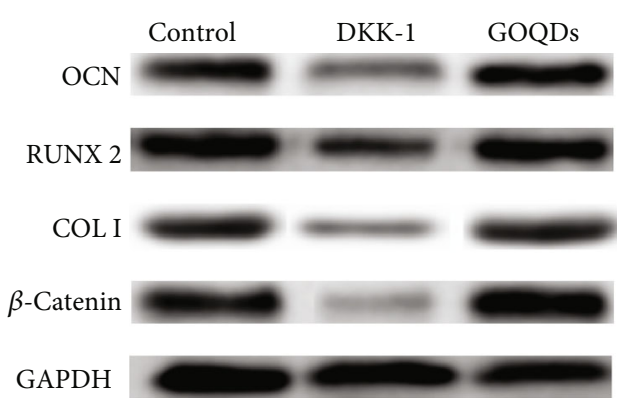

(c)
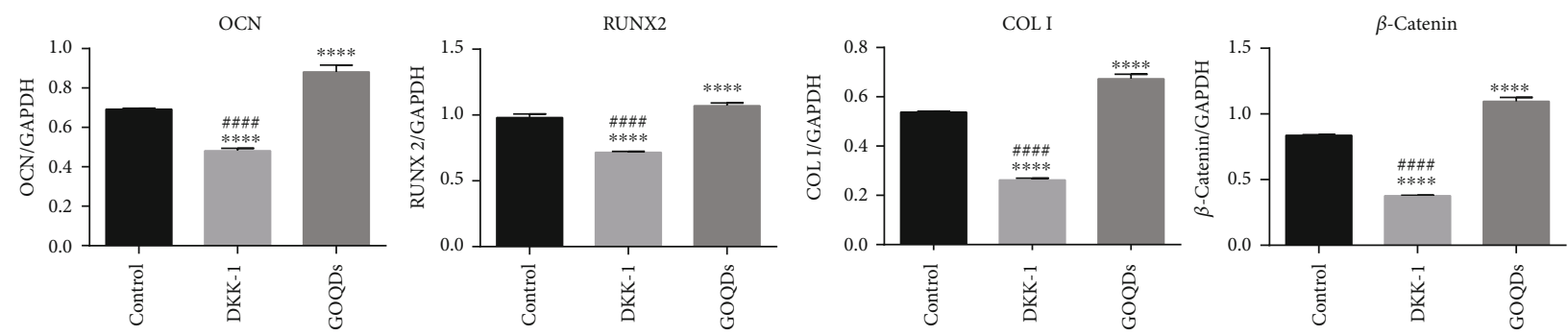

(d)

FIGURE 6: SHEDs were cultured in the osteogenic induction medium containing GOQDs and/without DKK-1. (a) mRNA extracted at 7 days. (b) mRNA extracted at 14 days. (c) Protein extracted at 14 days. (d) Quantification of protein levels. ${ }^{*} p<0.05,{ }^{* *} p<0.01,{ }^{* * *} p<0.001$, and

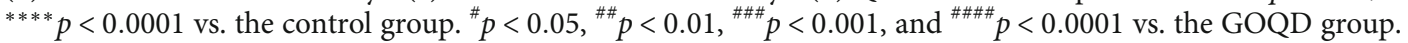

dot using physical, chemical, or electrochemical methods [14]. The bottom-up method uses specific molecular precursors that undergo a gradual chemical reaction to synthesize GOQDs [14]. In this study, we prepared GOQDs using a bottom-up method by pyrolyzing CA [27]. Figure 1 presents a characterization of the GOQDs in this study, showing that they generally had diameters under $10 \mathrm{~nm}$ and presented hydrophilicity and PL. In contrast to organic quantum dots, inorganic quantum dots, and fluorescent agents, the most advantageous properties of the GOQDs in this study were their stable PL, good hydrophilicity, and low cytotoxicity [28].
A cytotoxicity assessment was conducted to determine the appropriate concentration of GOQDs to induce SHED proliferation. Cell growth curves are often used to measure logarithmic growth, which reflects the effects of materials on cell viability [29]. A cell growth curve consists of four stages: plateau, logarithmic growth, second plateau, and degenerate aging [29]. As seen in Figure 2, SHEDs demonstrated a strong self-renewal ability and could grow and proliferate in a culture medium that contained a suitable amount of GOQDs. Therefore, GOQD concentrations of 1, 10, and $50 \mu \mathrm{g} / \mathrm{mL}$ GOQDs were used in subsequent experiments. This matched the concentrations of graphene quantum dots 


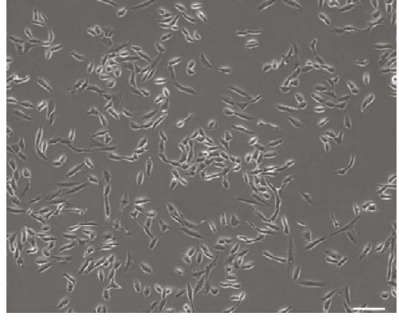

(A)

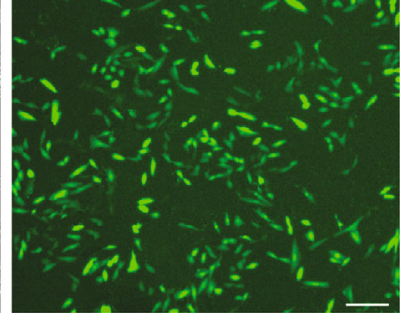

(B)

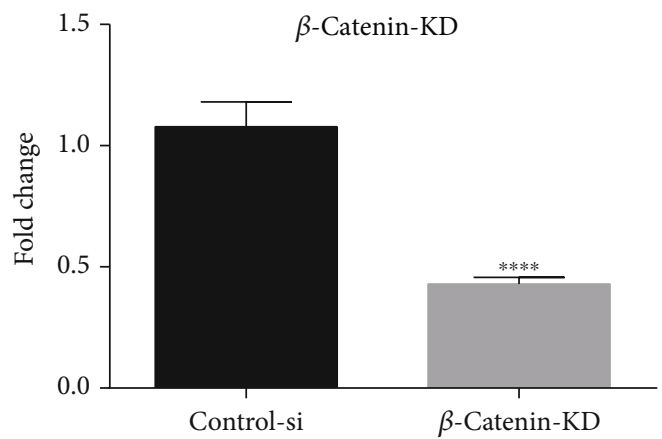

(b)

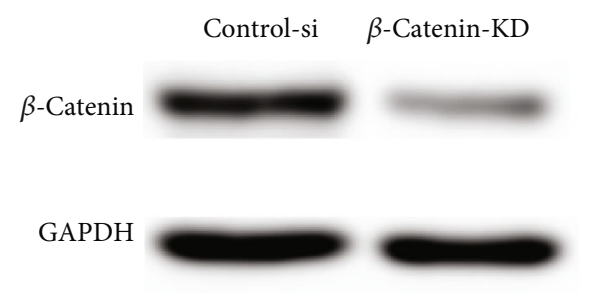

(c)

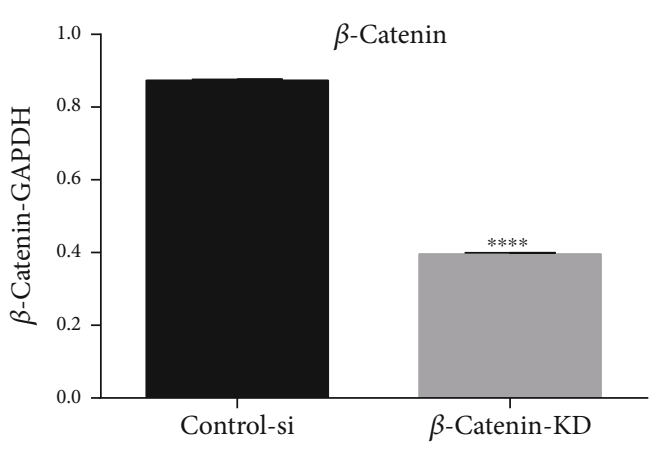

(d)

Figure 7: (a) A green fluorescence protein marker was used to determine the transfer efficiency of $\beta$-catenin knockdown in SHEDs (SHEDsi). After transfection for $72 \mathrm{~h}$, cells were observed under a (A) contrast phase microscope and an (B) immunofluorescence microscope. Scale bar, $100 \mu \mathrm{m}$. (b) qRT-PCR analysis was performed to detect $\beta$-catenin expression. (c) WB was conducted to determine $\beta$-catenin. (d) Quantification of $\beta$-catenin protein levels. ${ }^{*} p<0.05$ vs. the control-si group.

(GQDs) used by Qiu et al. [30]. Their group found that GQDs at the concentrations of 1,10 , and $50 \mu \mathrm{g} / \mathrm{mL}$ did not significantly inhibit mesenchymal stem cell (MSC) proliferation.

Many researchers are currently employing GOQDs in cell imaging [19, 28], real-time molecular tracking of living cells [31], and in vivo optical imaging [32]. Zhang et al. [28] used GQDs in cell imaging and found that they could enter stem cells easily, had low cytotoxicity, and produced clear and stable stem cell images. Kim et al. [33] demonstrated that GQDs could be used as biological imaging probes to track human adipose-derived stem cells due to their good biocompatibility and highly sensitive optical properties. In this study, we found that GOQDs could be used as a live cell imaging agent. SHEDs emitted green fluorescence and maintained normal stem cell morphology after incubation with GOQDs (Figure 3).

Next, the effects of GOQD exposure on the osteogenic differentiation of SHEDs were evaluated. Mineralized nodules were significantly increased in the $10 \mu \mathrm{g} / \mathrm{mL}$ GOQD group (Figure 4(a)), indicating that this might be a suitable concentration for inducing SHED osteogenic differentiation. However, GOQDs helped promote SHED proliferation, resulting in an increased number of cells. It was therefore necessary to more precisely determine whether the increased number of mineralized nodules in the GOQD group was due to more cells or the tendency of GOQDs to promote osteogenic differentiation. ALP activity assays were then per- formed. ALP is synthesized by osteoblasts during the early stage of osteogenic differentiation. Its activity reflects the ability of cells to mineralize [34,35]. Figure 4(b) shows that GOQDs at a concentration of $10 \mu \mathrm{g} / \mathrm{mL}$ had a stronger ability to induce SHED osteogenic differentiation in the early stage. The increase in ALP activity was concentration-dependent.

To investigate further, qRT-PCR and WB assays were used to measure the mRNA and protein expression of osteogenic-related markers. OCN is a matrix protein expressed in the early stages of mineralization and highly expressed in the late stages of osteoblastic differentiation, and it plays an important role in bone tissue mineralization [36]. RUNX2 is an essential transcription factor expressed in the late stages of mineralization that plays a central role in the signal transduction pathway during osteogenic differentiation [37]. COL I is a type of collagen that provides a structure for mineralization; it is an important early expressed protein in osteogenic differentiation [38]. Figure 5 shows the qRT-PCR and WB results, which were consistent with those of alizarin red staining and ALP activity assays. At a concentration of $10 \mu \mathrm{g} / \mathrm{mL}$, GOQDs had a stronger ability to induce osteogenic differentiation in SHEDs, while it was slightly inhibited at $50 \mu \mathrm{g} / \mathrm{mL}$. However, Qiu et al. [30] found that $50 \mu \mathrm{g} / \mathrm{mL}$ GQDs had a better ability to induce MSC osteogenic differentiation, while $10 \mu \mathrm{g} / \mathrm{mL}$ GQDs had a greater ability to induce lipogenic differentiation in MSCs. The different physical and chemical properties of GOQDs and GQDs may be the reason for this discrepancy. 

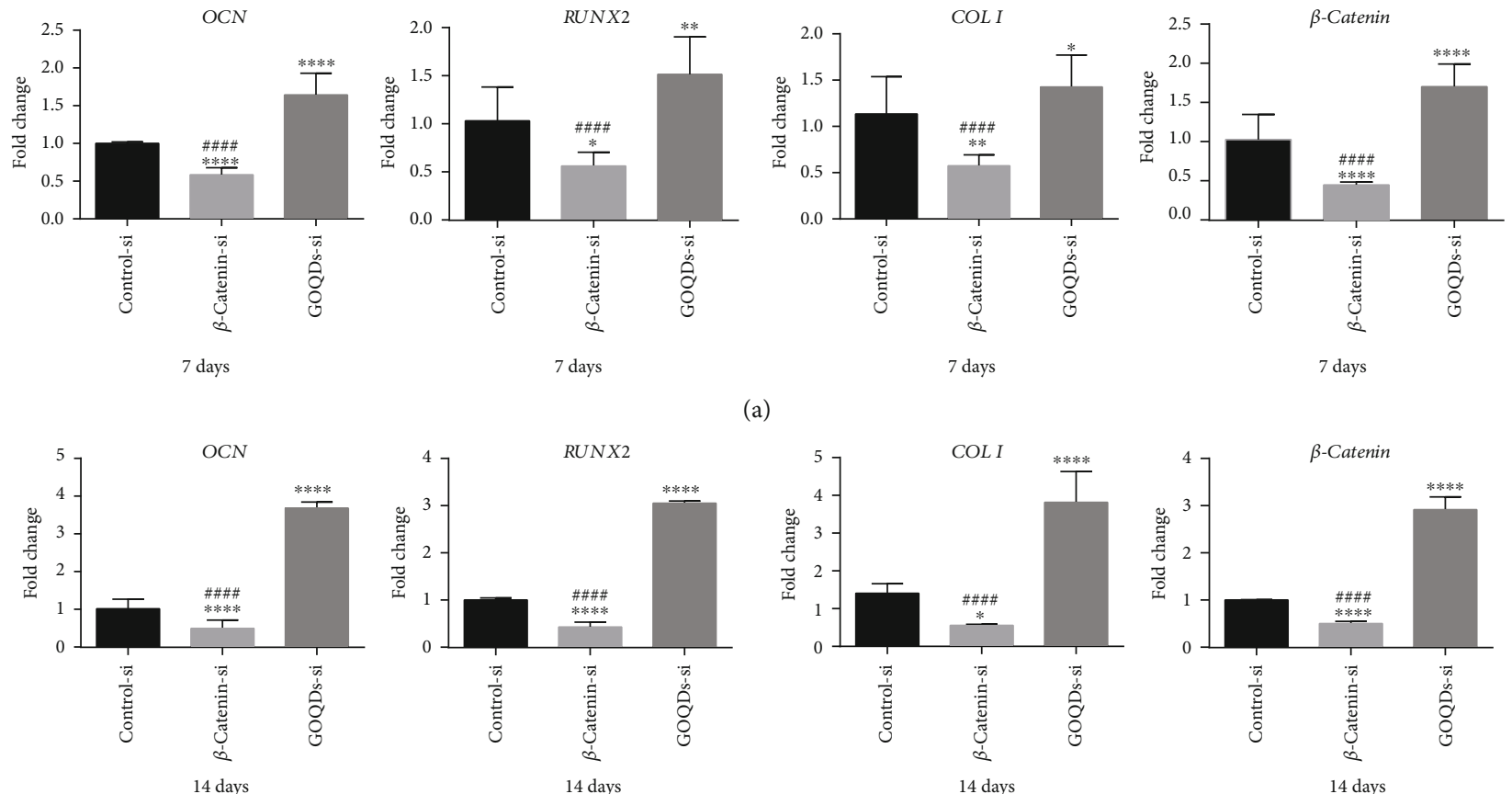

(a)
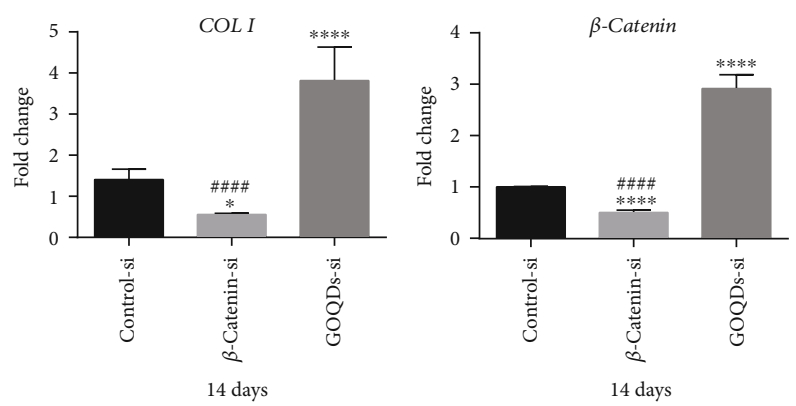

(b)

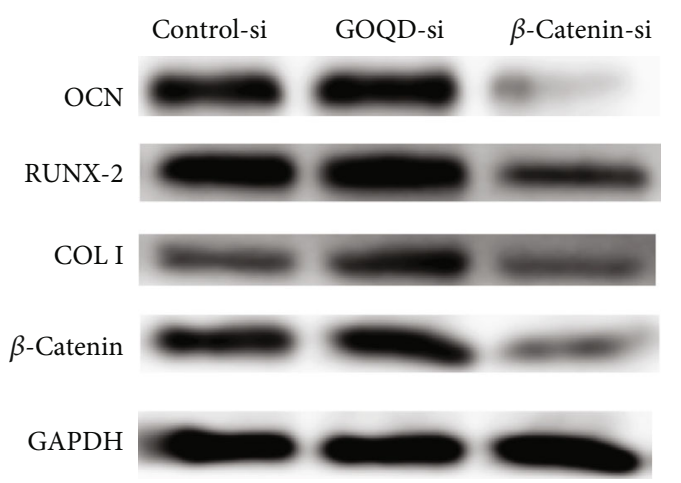

(c)
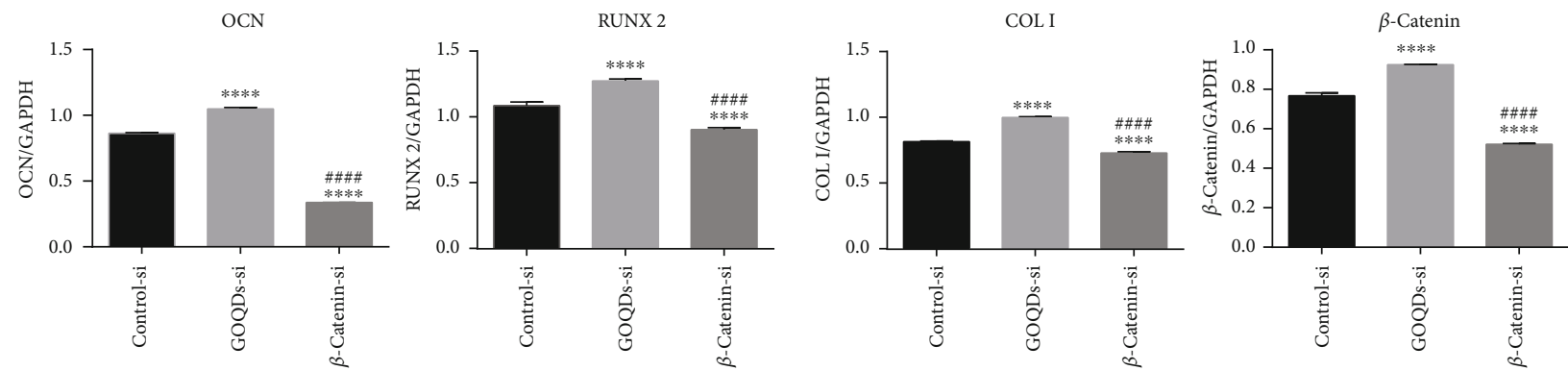

(d)

FIGURE 8: SHEDs were cultured in the osteogenic induction medium containing GOQDs. (a) mRNA extracted at 7 days. (b) mRNA extracted at 14 days. (c) Protein extracted at 14 days. (d) Quantification of protein levels. ${ }^{*} p<0.05,{ }^{* *} p<0.01,{ }^{* * *} p<0.001$, and ${ }^{* * * *} p<0.0001$ vs. the control-si group. ${ }^{\#} p<0.05,{ }^{\# \#} p<0.01,{ }^{\# \#} p<0.001$, and ${ }^{\# \# \#} p<0.0001$ vs. the $\beta$-catenin-si group.

In addition, Geng et al. [39] found that $10 \mu \mathrm{g} / \mathrm{mL}$ nitrogendoped GQDs (N-GQDs) were better able to induce osteogenic differentiation in bone MSCs than $50 \mu \mathrm{g} / \mathrm{mL}$ N-GQDs, matching the optimal concentration of GOQDs found in this study.

The mRNA and protein expression trends of the $\mathrm{Wnt} / \beta$ catenin signaling pathway-related factor, $\beta$-catenin, were in accordance with those of OCN, RUNX2, and COL I. Upregulated $\beta$-catenin and its nuclear translocation are considered markers of $\mathrm{Wnt} / \beta$-catenin pathway activation $[22,23]$. Therefore, we speculated that the $\mathrm{Wnt} / \beta$-catenin signaling pathway might regulate the GOQD-mediated induction of osteogenic differentiation in SHEDs. DKK-1 is an inhibitor of the Wnt/ $\beta$-catenin signaling pathway [40], which can bind 
to the low-density lipoprotein receptor-related proteins 5 and 6 and then prevent their combination with Frizzled, thus inhibiting accumulation of $\beta$-catenin in the cytoplasm and blocking signal transduction of the $\mathrm{Wnt} / \beta$-catenin signaling pathway $[41,42]$. In this study, we added DKK-1 to the $10 \mu \mathrm{g} / \mathrm{mL}$ GOQD group to verify whether this could antagonize GOQD-induced osteogenic differentiation in SHEDs and preliminarily explored how the $\mathrm{Wnt} / \beta$-catenin signaling pathway regulates this process. The results are shown in Figure 6. DKK-1 inhibited the signaling pathway and reduced $\beta$-catenin expression, thus antagonizing the ability of GOQDs to induce osteogenic differentiation in SHEDs. To confirm this, $\beta$-catenin was silenced (Figure 7 ), and the results of the effect of $\beta$-catenin knockdown on SHED osteogenic differentiation are shown in Figure 8. $\beta$-Catenin knockdown reduced OCN, RUNX2, and COL I at the mRNA and protein levels, which supports our assessment of the effects of DKK-1.

Finally, the in vitro results demonstrated that GOQDs promote SHED proliferation and osteogenic differentiation in a concentration-dependent manner and that the $\mathrm{Wnt} / \beta$ catenin signaling pathway is activated during this process. However, further in vivo research is necessary to verify these results.

\section{Conclusion}

GOQDs promote concentration-dependent proliferation and osteogenic differentiation of SHEDs, and the $\mathrm{Wnt} / \beta$-catenin signaling pathway is involved in regulating these effects. This work provides new ideas and fundamental information on the interactions between GOQDs and SHEDs that are relevant for the biomedical engineering field.

\section{Data Availability}

The data used to support the findings of this study are available from the corresponding authors upon request.

\section{Conflicts of Interest}

There are no competing financial interests among the authors.

\section{Authors' Contributions}

Xin Yang and Qi Zhao contributed equally to this work. Xin Yang and Qi Zhao are co-first authors.

\section{Acknowledgments}

This project was funded by the National Natural Science Foundation of China (81974146 and 81873711), the Natural Science Foundation of Guangdong Province (2014A030313126), the Science and Technology Planning Project of Guangdong Province (2016A020215094), and the Guangdong Medical Science and Technology Research Foundation (A2015396).

\section{References}

[1] J. Henkel, M. A. Woodruff, D. R. Epari et al., "Bone regeneration based on tissue engineering conceptions - a 21st century perspective," Bone Research, vol. 1, no. 3, pp. 216-248, 2013.

[2] L. Ma, R. Aijima, Y. Hoshino et al., "Transplantation of mesenchymal stem cells ameliorates secondary osteoporosis through interleukin-17-impaired functions of recipient bone marrow mesenchymal stem cells in MRL/lpr mice," Stem Cell Research \& Therapy, vol. 6, no. 1, article 104, 2015.

[3] B. Akar, A. M. Tatara, A. Sutradhar et al., "Large animal models of an in vivo bioreactor for engineering vascularized bone," Tissue Engineering Part B: Reviews, vol. 24, no. 4, pp. 317-325, 2018.

[4] D. Gan, M. Liu, T. Xu, K. Wang, H. Tan, and X. Lu, "Chitosan/biphasic calcium phosphate scaffolds functionalized with BMP-2-encapsulated nanoparticles and RGD for bone regeneration," Journal of Biomedical Materials Research Part A, vol. 106, no. 10, pp. 2613-2624, 2018.

[5] M. Miura, S. Gronthos, M. Zhao et al., "SHED: stem cells from human exfoliated deciduous teeth," Journal of Dental Research, vol. 100, no. 10, pp. 5807-5812, 2003.

[6] F. A. Ishiy, R. D. Fanganiello, K. Griesi-Oliveira et al., "Improvement of in vitro osteogenic potential through differentiation of induced pluripotent stem cells from human exfoliated dental tissue towards mesenchymal-like stem cells," Stem Cells International, vol. 2015, 249099 pages, 2015.

[7] J. Suchanek, K. T. Suchankova, V. Rehacek, K. Z. Browne, and T. Soukup, "Proliferative capacity and phenotypical alteration of multipotent ecto-mesenchymal stem cells from human exfoliated deciduous teeth cultured in xenogeneic and allogeneic media," Folia Biologica, vol. 62, no. 1, pp. 1-14, 2016.

[8] Y. Nishino, Y. Yamada, K. Ebisawa et al., "Stem cells from human exfoliated deciduous teeth (SHED) enhance wound healing and the possibility of novel cell therapy," Cytotherapy, vol. 13, no. 5, pp. 598-605, 2011.

[9] G. Akpinar, M. Kasap, A. Aksoy, G. Duruksu, G. Gacar, and E. Karaoz, "Phenotypic and proteomic characteristics of human dental pulp derived mesenchymal stem cells from a natal, an exfoliated deciduous, and an impacted third molar tooth," Stem Cells International, vol. 2014, 2014.

[10] Y. Li, Y. Y. Yang, J. L. Ren, F. Xu, F. M. Chen, and A. Li, "Exosomes secreted by stem cells from human exfoliated deciduous teeth contribute to functional recovery after traumatic brain injury by shifting microglia M1/M2 polarization in rats," Stem Cell Research \& Therapy, vol. 8, no. 1, p. 198, 2017.

[11] T. Yamaza, A. Kentaro, C. Chen et al., "Immunomodulatory properties of stem cells from human exfoliated deciduous teeth," Stem Cell Research \& Therapy, vol. 1, no. 1, p. 5, 2010.

[12] E. P. Chalisserry, S. Y. Nam, S. H. Park, and S. Anil, “Therapeutic potential of dental stem cells," Journal of Tissue Engineering, vol. 8, 2017.

[13] X. Yang, Q. Zhao, Y. Chen et al., "Effects of graphene oxide and graphene oxide quantum dots on the osteogenic differentiation of stem cells from human exfoliated deciduous teeth," Artificial Cells, Nanomedicine and Biotechnology, vol. 47, no. 1, pp. 822-832, 2019.

[14] L. Li, G. Wu, G. Yang, J. Peng, J. Zhao, and J. J. Zhu, "Focusing on luminescent graphene quantum dots: current status and future perspectives," Nanoscale, vol. 5, no. 10, pp. 4015-4039, 2013. 
[15] S. Zhu, J. Zhang, C. Qiao et al., "Strongly greenphotoluminescent graphene quantum dots for bioimaging applications," Chemical Communications, vol. 47, no. 24, pp. 6858-6860, 2011.

[16] X. Ji, B. Xu, M. Yao et al., "Graphene oxide quantum dots disrupt autophagic flux by inhibiting lysosome activity in GC-2 and TM4 cell lines," Toxicology, vol. 374, pp. 10-17, 2016.

[17] X. Zhou, P. Ma, A. Wang et al., "Dopamine fluorescent sensors based on polypyrrole/graphene quantum dots core/shell hybrids," Biosensors \& Bioelectronics, vol. 64, pp. 404-410, 2015.

[18] M. Liu, R. Zhang, and W. Chen, "Graphene-supported nanoelectrocatalysts for fuel cells: synthesis, properties, and applications," Chemical Reviews, vol. 114, no. 10, pp. 5117-5160, 2014.

[19] H. Sun, L. Wu, N. Gao, J. Ren, and X. Qu, "Improvement of photoluminescence of graphene quantum dots with a biocompatible photochemical reduction pathway and its bioimaging application," ACS Applied Materials \& Interfaces, vol. 5, no. 3, pp. 1174-1179, 2013.

[20] C. Wang, C. Wu, X. Zhou et al., "Enhancing cell nucleus accumulation and DNA cleavage activity of anti-cancer drug via graphene quantum dots," Scientific Reports, vol. 3, no. 1, p. 2852, 2013.

[21] S. Y. Choi, S. H. Baek, S. J. Chang et al., "Synthesis of upconversion nanoparticles conjugated with graphene oxide quantum dots and their use against cancer cell imaging and photodynamic therapy," Biosensors \& Bioelectronics, vol. 93, pp. 267-273, 2017.

[22] X. Yang, S. J. Li, and W. Zhao, "Wnt signaling pathway mediates the dental pulp stem cells in multipotential differentiation and inflammatory microenvironment," International Journal of Stomatology, vol. 3, pp. 286-290, 2018.

[23] T. Reya and H. Clevers, "Wnt signalling in stem cells and cancer," Nature, vol. 434, no. 7035, pp. 843-850, 2005.

[24] S. Jiang, G. Chen, L. Feng et al., "Disruption of kif3a results in defective osteoblastic differentiation in dental mesenchymal stem/precursor cells via the Wnt signaling pathway," Molecular Medicine Reports, vol. 14, no. 3, pp. 1891-1900, 2016.

[25] B. Li, C. Qu, C. Chen et al., "Basic fibroblast growth factor inhibits osteogenic differentiation of stem cells from human exfoliated deciduous teeth through ERK signaling," Oral Diseases, vol. 18, no. 3, pp. 285-292, 2012.

[26] Y. Liu, C. Chen, S. Liu et al., "Acetylsalicylic acid treatment improves differentiation and immunomodulation of SHED," Journal of Dental Research, vol. 94, no. 1, pp. 209-218, 2014.

[27] Y. Dong, J. Shao, C. Chen et al., "Blue luminescent graphene quantum dots and graphene oxide prepared by tuning the carbonization degree of citric acid," Carbon, vol. 50, no. 12, pp. 4738-4743, 2012.

[28] M. Zhang, L. Bai, W. Shang et al., "Facile synthesis of watersoluble, highly fluorescent graphene quantum dots as a robust biological label for stem cells," Journal of Materials Chemistry, vol. 22, no. 15, pp. 7461-7467, 2012.

[29] N. Zhao, L. Zeng, Y. Liu et al., "DLX3 promotes bone marrow mesenchymal stem cell proliferation through H19/miR-675 axis," Clinical Science, vol. 131, no. 22, pp. 2721-2735, 2017.

[30] J. Qiu, D. Li, X. Mou et al., "Effects of graphene quantum dots on the self-renewal and differentiation of mesenchymal stem cells," Advanced Healthcare Materials, vol. 5, no. 6, pp. 702$710,2016$.
[31] J. Peng, W. Gao, B. K. Gupta et al., "Graphene quantum dots derived from carbon fibers," Nano Letters, vol. 12, no. 2, pp. 844-849, 2012.

[32] M. Nurunnabi, Z. Khatun, M. Nafiujjaman, D. G. Lee, and Y. K. Lee, "Surface coating of graphene quantum dots using mussel-inspired polydopamine for biomedical optical imaging," ACS Applied Materials \& Interfaces, vol. 5, no. 16, pp. 8246-8253, 2013.

[33] J. Kim, S. H. Song, Y. Jin et al., "Multiphoton luminescent graphene quantum dots for in vivo tracking of human adiposederived stem cells," Nanoscale, vol. 8, no. 16, pp. 8512-8519, 2016.

[34] C. T. Brighton, J. R. S. Fisher JR., S. E. Levine et al., "The biochemical pathway mediating the proliferative response of bone cells to a mechanical stimulus*," Journal of Bone and Joint Surgery, vol. 78, no. 9, pp. 1337-1347, 1996.

[35] Y. Tsukamoto, S. Fukutani, T. Shin-ike et al., "Mineralized nodule formation by cultures of human dental pulp-derived fibroblasts," Archives of Oral Biology, vol. 37, no. 12, pp. 1045-1055, 1992.

[36] M. Rahnama, I. Jastrzębska-Jamrogiewicz, R. Jamrogiewicz, and G. Trybek, "Analysis of the influence of hormone replacement therapy on osteocalcin gene expression in postmenopausal women," BioMed Research International, vol. 2015, 8 pages, 2015.

[37] L. Dalle Carbonare, G. Innamorati, and M. T. Valenti, “Transcription factor Runx2 and its application to bone tissue engineering," Stem Cell Reviews and Reports, vol. 8, no. 3, pp. 891897, 2012.

[38] M. Y. Kuo, W. H. Lan, S. K. Lin, K. S. Tsai, and L. J. Hahn, "Collagen gene expression in human dental pulp cell cultures," Archives of Oral Biology, vol. 37, no. 11, pp. 945-952, 1992.

[39] H. Geng, J. Qiu, H. Zhu, and X. Liu, "Achieving stem cell imaging and osteogenic differentiation by using nitrogen doped graphene quantum dots," Journal of Materials Science: Materials in Medicine, vol. 29, no. 6, p. 85, 2018.

[40] B. Mao, W. Wu, G. Davidson et al., "Kremen proteins are Dickkopf receptors that regulate $\mathrm{Wnt} / \beta$-catenin signalling," Nature, vol. 417, no. 6889, pp. 664-667, 2002.

[41] B. Mao, W. Wu, Y. Li et al., "LDL-receptor-related protein 6 is a receptor for Dickkopf proteins," Nature, vol. 411, no. 6835, pp. 321-325, 2001.

[42] S. M. Huang, Y. M. Mishina, S. Liu et al., "Tankyrase inhibition stabilizes axin and antagonizes Wnt signalling," Nature, vol. 461, no. 7264, pp. 614-620, 2009. 